\title{
Case: Primary erectile dysfunction due to congenital isolated cavernous bodies
}

\author{
Katherine I. Henriquez, MD; Gerald Brock, MD \\ Division of Urology, Department of Surgery, University of Western Ontario, London, ON, Canada
}

Cite as: Can Urol Assoc J 2017;11 (9):E385-7. http://dx.doi.org/10.5489/cuaj.4521

Published online September 12, 2017

\section{Introduction}

The finding of a complete penile corporal septum is a rare malformation in which the corpora cavernosa are completely isolated and function independently. Keogh was the first to reference this in 1989. ${ }^{1}$ Kolbenstvedt reported what was thought to be a source of error in pressure recordings or in intracavernous injection. ${ }^{2}$ Gorga, in 1991, described isolated cavernous bodies in a patient with erectile dysfunction (ED). ${ }^{3}$ This abnormality may be associated with corporal veno-occlusive dysfunction and hypoplastic cavernous arteries. It can be recognized incidentally during penile duplex ultrasound (DUS), when a vasoactive agent is injected into one corpus cavernosum, producing tumescence in one side while the contralateral corporal body remains flaccid, requiring a contralateral injection to obtain a complete erection.

\section{Case report}

A 37-year-old man was referred for assessment of a lifelong inability to achieve and maintain erections. He presented with an Erection Hardness Score (EHS) of 1/4 and International Index of Erectile Function 5 (IIEF-5) score of $4 / 25$, even with self-stimulation and various partners. He reported normal libido and normal ejaculatory function. He denied having morning erections, penile curvature, penile pain, or pelvic trauma. He tried phosphodiesterase 5 inhibitors (PDE5i) without success and needed to use bilateral intracavernosal injections $(\mathrm{ICl})$ to obtain an erection adequate for intercourse. He had been diagnosed as having hypogonadism and was treated with testosterone.

His medical history was unremarkable apart from hypothyroidism and gastro-esophageal reflux disease.

Secondary sex characteristics were developed and normal. The external genitalia exam demonstrated a penis of normal size without palpable scarring or deformities. Testes were normal in location, size, and consistency.

The penile DUS revealed unilateral tumescence in the left corpus cavernosum that was initially injected 5 ug of prostaglandin E-1 (PGE-1) (Fig. 1A). The peak cavernosal arterial flow was normal and increased only on the injected side (Fig. 1B). A second injection of 5 ug PGE-1 was administered into his right corpus cavernosum to achieve a complete erection (Fig. 1C). The cavernosal arteries demonstrated normal flow without veno-occlusive dysfunction, as determined by diastolic flow $<5 \mathrm{~cm} / \mathrm{second}$ (Fig. 1D).

\section{Discussion}

In contrast to many other mammalian species, in man, normal development of the penile corpora cavernosa results in an incomplete midline septum between the cavernous bodies, with communication through vascular fenestrations. The septum becomes more complete at the tip of the penis and at the hilum, where the corpora cavernosa separate to form two distinct penile crura. This is different than in dogs, where a complete septum exists through the entire penile length, resulting in independently functioning corpora, albeit with the aid of a residual os penis. ${ }^{4}$

In the literature, nine cases of congenital isolated cavernous bodies have been reported since 1989. The previous cases have been diagnosed using nocturnal penile tumescence (NPT), penile DUS, cavernosometry, and cavernosography in patients between 37 and 41 years old with primary ED (Table 1).

While in patients with normal anatomy, unilateral cavernosal injection of vasoactive drugs produce bilateral corporal rigidity and symmetrical waveform changes in the cavernosal arteries, in patients with a complete penile corporal septum, the contralateral corporal body remains flaccid. Bilateral injection is required to evaluate cavernosal artery velocity and to induce a complete erection. If it is not recognized, low velocity flows in the opposite cavernosal artery might be mistaken as cavernosal arterial insufficiency. Colour Doppler ultrasound evaluation of the cavernous arteries without vasoactive $\mathrm{ICl}$ is not a reliable measure to detect this abnormality.

Establishing a diagnosis of a complete penile corporal septum was historically made with cavernosography, ${ }^{5}$ which 


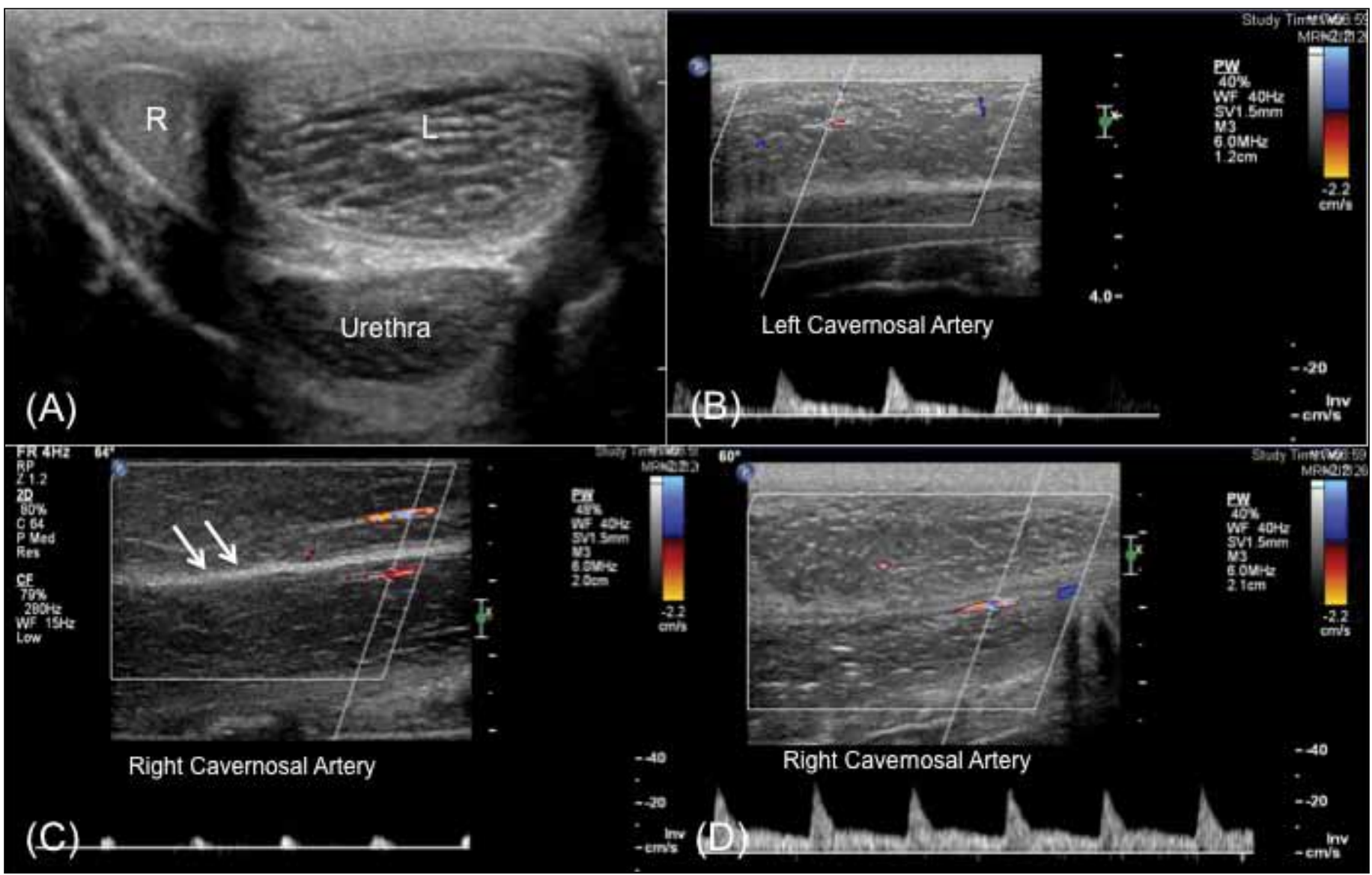

Fig. 1. Penile Duplex ultrasound of congenital isolated cavernous bodies demonstrates: $(\boldsymbol{A})$ unilateral dilation of his left cavernous body after injection of 5 ug prostaglandin E-1 (PGE-1) without dilation of the right cavernous body; and (B) left cavernosal artery had a peak systolic velocity (PSV) of $20 \mathrm{~cm} / \mathrm{s}$. (C)The complete septum was identified (arrows) on the sagittal view when the right cavernosal artery did not increase after contralateral intracavernous injections. (D) After another injection of 5 ug PGE-1 into the right corpora, the right cavernosal artery dilated and demonstrated a PSV of $28 \mathrm{~cm} / \mathrm{s}$.

demonstrates that injection of iodinated contrast agent in one corpus cavernosum fails to communicate with the contralateral side. ${ }^{6}$ The images reveal unilateral corporal opacification; however, cavernosography is an invasive method that is no longer needed in most cases, reducing potential complications, as it provides no functional information on vascular status.
Bertolotto et al demonstrated in two cases that contrastenhanced US could be used as effectively as cavernosography to diagnose a complete penile corporal septation. ${ }^{7}$ Contrast-enhanced US showed unilateral enhancement of the corpus cavernosum in which microbubbles had been injected, while the contralateral corpus cavernosum remained unenhanced. This technique is simple and can

\section{Table 1. Diagnostic findings in cases of congenital isolated cavernous bodies}

\begin{tabular}{lcc}
\hline Investigation & Findings \\
\hline $\begin{array}{l}\text { Nocturnal penile } \\
\text { tumescence }\end{array}$ & Multiple erectile episodes with subnormal rigidity and tumescence \\
\hline $\begin{array}{l}\text { Penile Duplex } \\
\text { ultrasound }\end{array}$ & $\begin{array}{c}\text { Cavernosal artery peak systolic velocity increased only in the injected side } \\
\text { When a vasoactive agent is injected into one corpus cavernosum, it produces unilateral } \\
\text { tumescence while the contralateral corporal body remains flaccid }\end{array}$ \\
\hline $\begin{array}{l}\text { Cavernosometry } \\
\text { Cavernosography }\end{array}$ & $\begin{array}{c}\text { Intracavernous pressure in one side may reach } 150 \mathrm{mmH} \text { with a saline infusion rate of } \\
50 \mathrm{ml} / \mathrm{min} \text {, but contralateral side remains flaccid with no increase in pressure }\end{array}$ \\
\hline $\begin{array}{l}\text { Contrast-enhanced } \\
\text { ultrasound }\end{array}$ & $\begin{array}{c}\text { Enhancement of the corpus cavernosum in which microbubbles are injected, while the } \\
\text { the other side; unilateral corporal opacification is seen } \\
\text { contralateral corpus cavernosum remains unenhanced }\end{array}$ \\
\hline
\end{tabular}


be rapidly performed after conventional Doppler study, but requires specific software.

The differential diagnosis that should been considered in these cases includes corporal fibrosis and hypoplasia of the corpora cavernosa. When a man with a complete penile corporal septum tries to achieve an erection, the intracorporal pressures are not equivalent in both sides. This can produce variable hardness of one corpus cavernosum compared to the other, producing buckling of the penis with lateral deformity during intercourse.

Isolated cavernous bodies were classically treated with bilateral ICl as first-line therapy; ${ }^{8}$ however, most of the published cases were reported before 1998, when PDE5i first became available. The treatment response helps to diagnose a complete penile corpora septum. This includes a delayed erection response to PDE5i due to lack of pressure compensation side to side, unilateral tumescence with $\mathrm{ICl}$, and full erection with bilateral ICI.

Matter et al described that complete septum of the cavernous bodies in itself is insufficient to cause ED. Therefore, optimal treatment depends on determining the underlying arterial, veno-occlusive, neurogenic, and psychogenic contributing factors. ${ }^{9}$ There are probably many patients with this anomaly who never seek or require treatment. Systemic therapy with PDE5i can produce a good response in patients without veno-occlusive dysfunction and likely represents a better option than bilateral IC injections. Intraurethral alprostadil can also be used as local treatment, where PGE-1 is absorbed through the urethra, but is costly, and its reported efficacy of $56 \%$ is lower than $\mathrm{ICl}^{10}$

\section{Conclusion}

Isolated cavernous bodies is a congenital malformation that can produce primary erectile dysfunction, characterized by lateral deformity, hinge defect of the shaft, and poor response to PDE5i. The diagnosis is most easily made by penile DUS.
Cavernosometry and cavernosography are no longer typically necessary. A stepwise approach to treatment is suggested, with PDE5i, ICl of vasoactive agents, and consideration of an inflatable penile prosthesis implant in treatment refractory cases. If $\mathrm{ICl}$ is used, it will require direct delivery of the vasoactive agent into each corpora cavernosum.

Competing interests: The authors report no competing personal or financial interests.

This paper has been peer-reviewed.

\section{References}

1. Keogh EJ. Absent cross-circulation between corpora cavernosa. J Urol 1989;142:1335. https://doi. org/10.1016/50022-5347(17)39091-2

2. Kolbenstvedt A, Egge T, Klevmark B, et al. Isolated cavernous bodies. J Urol 1990;143:356-7. https://doi.org/10.1016/S0022-5347(17)39961-5

3. Gorga CF, Begliomini H, Mascarenhas RJ. Absent communication between cavernous bodies: A real possibility. Urology 1991;38:94. https://doi.org/10.1016/0090-4295(91)80028-6

4. Fournier GR Jr, Juenemann KP, Lue TF, et al. Mechanisms of venous occlusion during canine penile erection: An anatomic demonstration. J Urol 1987;137:163-7. https://doi.org/10.1016/S0022$5347(17) 43911-5$

5. Hollander JB, Stiff CA. Complete penile corporal septation. J Urol 1996;155:647. https://doi. org/10.1016/50022-5347(01)66481-4

6. Montague DK, Lakin MM, Angermeier KW, et al. Primary erectile dysfunction in a man with congenital isolation of the corpora cavernosa. Urology 1995;46:114-6. https://doi.org/10.1016/S00904295(99)80175-7

7. Bertolotto M, Bucci S, Quaia E, et al. Complete penile corporeal septation: Evaluation with contrastenhanced ultrasound. Abdom Imaging 2008;33:621-5. https://doi.org/10.1007/s00261-008-9400-z

8. Tarhan F, Kuyumcuoglu U, Ergen M, et al. Congenitally isolated cavernous bodies. Int J Urol 1998:5:299300. https://doi.org/10.1111/j.1442-2042.1998.tb00609.x

9. Matter LE, Hailemariam $S$, Huch RA, et al. Primary erectile dysfunction in combination with congenital malformation of the cavernous bodies. Urol Int 1998;60:175-7. https://doi.org/10.1159/000030245

10. Guay AT, Perez JB, Velásquez $E$, et al. Clinical experience with intraurethral alprostadil (MUSE) in the treatment of men with erectile dysfunction. A retrospective study. Eur Urol 2000;38:671-6. https://doi.org/10.1159/000020360

Correspondence: Dr. Katherine I. Henriquez, Division of Urology, Department of Surgery, University of Western Ontario, London, ON, Canada; kativonhe@gmail.com 